\title{
RETRACTED ARTICLE: The Effect of Solute Atoms on Grain Boundary Migration: A Solute Pinning Approach
}

\author{
EMMANUEL HERSENT, KNUT MARTHINSEN, and ERIK NES
}

DOI: $10.1007 / \mathrm{s} 11661-012-1552-3$

(C) The Minerals, Metals \& Materials Society and ASM International 2013

THIS article has been retracted because of several unattributed quotations in the introductory section. A revised version of this article will be published.

EMMANUEL HERSENT, Researcher, KNUT MARTHINSEN, Professor, and ERIK NES, Professor Emeritus, are with the Department of Materials Science and Technology, Norwegian University of Science and Technology (NTNU), 7034, Trondheim, Norway. Contact e-mail: knut.marthinsen@material.ntnu.no

Manuscript submitted June 12, 2012. 